\title{
BMJ Open Magnitude and determinants of road traffic accidents in Northern Ethiopia: a cross-sectional study
}

\author{
Awtachew Berhe Woldu, ${ }^{1}$ Abraham Aregay Desta (D) ,2 \\ Tewolde Wubayehu Woldearegay (10 ${ }^{3}$
}

To cite: Woldu AB, Desta AA, Woldearegay TW. Magnitude and determinants of road traffic accidents in Northern Ethiopia: a cross-sectional study. BMJ Open 2020;10:e034133. doi:10.1136/ bmjopen-2019-034133

- Prepublication history for this paper is available online To view these files, please visit the journal online (http://dx.doi org/10.1136/bmjopen-2019034133).

Received 11 October 2019 Revised 26 January 2020 Accepted 03 February 2020
Check for updates

(C) Author(s) (or their employer(s)) 2020. Re-use permitted under CC BY-NC. No commercial re-use. See rights and permissions. Published by BMJ.

${ }^{1}$ School of Public Health, Ayder College of Health Sciences, Mekelle University, Mekelle, Ethiopia

${ }^{2}$ Directorate of Public Health Research and Emergency Management, Tigray Health Research Institute, Mekelle, Tigray, Ethiopia

${ }^{3}$ Tigray Health Research Institute, Mekelle, Tigray, Ethiopia

Correspondence to Abraham Aregay Desta; abaregaydesta@gmail.com

\section{ABSTRACT}

Objective This study aimed to assess the magnitude and determinants of road traffic accidents (RTAs) in Mekelle city, Northern Ethiopia.

Methods A cross-sectional study was done using a simple random sampling technique.

Setting The study was done in Mekelle city from February to June 2015.

Participants The study was done among drivers settled in Mekelle city.

Main outcome measures The main outcome measure was occurrence of RTA within 2 years. A binary logistic regression was used to identify factors associated with RTA.

Results The magnitude of RTA was found to be $23.17 \%$. According to the drivers' perceived cause of the accident, $22(38.60 \%)$ of the accident was due to violation of traffic rules and regulations. The majority of the victims were pedestrians, 19 (33.33\%). Drivers who were driving a governmental vehicle were 4.16 (adjusted OR (AOR) 4.16; $95 \% \mathrm{Cl} 1.48$ to 11.70 ) times more likely to have RTA compared with those who drive private vehicles. Drivers who used alcohol were 2.29 (AOR 2.29; $95 \% \mathrm{Cl} 1.08$ to 4.85) times more likely to have RTA compared with those drivers who did not consume alcohol.

Conclusion Magnitude of reported road traffic accident was high. Violation of traffic laws, lack of vehicle maintenance and lack of general safety awareness on pedestrians were the dominant reported causes of RTAs. Driving a governmental vehicle and alcohol consumption were the factors associated with RTA. Monitoring blood alcohol level of drivers and regular awareness to the drivers should be in place. Holistic study should be done to identify the causes of RTAs.

\section{INTRODUCTION}

Road traffic accident (RTA) is an accident, which occurs or originates on a way or street open to public traffic; resulting in one or more persons being killed or injured, and at least one moving vehicle is involved. RTA includes collisions between vehicles, vehicles and pedestrians and vehicles and animals or fixed obstacles. ${ }^{1}$ RTA contributes to poverty by causing loss of productivity, material damage, injuries, disabilities, grief and deaths. ${ }^{2}$ Deaths and injuries resulting from road traffic crashes remain

\section{Strengths and limitations of this study}

Data quality was assured under close supervision of the principal investigators.

- Appropriate statistical methods were used to present the findings of the study.

- Cross-sectional study design does not allow establishing causality.

- The analysis of this study misses some important variables like quality of the vehicles and road safety.

- There may be recall bias on the road traffic accidents occurrences.

a serious problem globally and current trends suggest that this will continue to be the case in the foreseeable future. ${ }^{34}$ RTA is the major cause of economic loss globally. The total costs to public services identified as follows: older drivers, $£ 63$ million ( $£ 10000$ per fatality); people driving for work, $£ 702$ million ( $£ 700000$ per fatality); motorcyclists, £1.1 billion ( $\$ 800000$ per fatality) and young drivers, $£ 1.3$ billion ( $£ 1.1$ million per fatality). ${ }^{5}$

Approximately 1.3 million people die each year in traffic-related accidents worldwide. ${ }^{6}$ Road traffic injury is now the leading cause of death for children and young adults aged 5-29 years, signalling a need for a shift in the current child health agenda. It is the eighthleading cause of death for all age groups exceeding HIV/AIDS, tuberculosis and diarrhoeal diseases ${ }^{7}$ and the deaths due to RTAs are predicted to become the fifth-leading cause of death by the year $2020 .^{6}$

The burden of road traffic injuries and deaths is disproportionately borne by vulnerable road users and those living in lowincome and middle-income countries, where the growing number of deaths is fuelled by transport that is increasingly motorised. Between 2013 and 2016, no reductions in the number of road traffic deaths were observed in any low-income country. ${ }^{2}$ Although road infrastructures have a significant role in the 
occurrence of RTA, the human factor is the most prevalent contributing factor of RTAs. This includes both driving behaviour (eg, drinking and driving, speeding, traffic law violations) and impaired skills (eg, lack of attention, exhaustion, physical disabilities and so on).$^{8}$

Poor conditions of quality of vehicles and less road safety are determinant factors for RTA in Africa ${ }^{9}$ including Ethiopia. ${ }^{10}$ WHO in 2011 reported that RTA in Ethiopia reached 22786 which accounted for $2.77 \%$ of all the deaths. The report showed that RTA is the ninth killer health problem in the country. RTA makes Ethiopia 12th and 9th in the world and in Africa, respectively. ${ }^{11}$ Mekelle is a fast growing regional city, which has a heavy traffic flow, especially during peak hours. ${ }^{12}$ In Mekelle city, it was reported that RTA is increasing from year to year and it was shown that $96 \%$ of the causes were related to human risky behaviour whereas $4 \%$ was due to vehicle-related factors. ${ }^{12}{ }^{13}$ However, despite the growing magnitude of RTAs in the city, there is paucity of data on determinants of RTAs among drivers. In addition, to that the study can have significant role to fill the lack of data as there is lack of reliable data although it is a serious problem in most of the low-income and middle-income countries. ${ }^{14}$ Hence, this study was conducted to assess the magnitude and determinants of RTAs among drivers in Mekelle city, Tigray, Ethiopia. This study can have a significant role in supplementing and informing the current status in achieving the United Nations (UN) Sustainable Development Goals (SDG) 3.6 for a reduction in the number of deaths by half by $2020 .^{15}$

\section{METHODS}

\section{Study setting}

The study was conducted among drivers in Mekelle city, Tigray, Northern Ethiopia from February to June 2015. Mekelle is the capital city of the Tigray regional state which is found at $783 \mathrm{Km}$ north of the capital city of Ethiopia, Addis Ababa. Regarding road infrastructure: Mekelle city has $55 \mathrm{~km}$ asphalted, $23 \mathrm{~km}$ cobble stone and $152 \mathrm{~km}$ gravel road. ${ }^{16}$

\section{Study design}

A cross-sectional study design was used.

\section{Participants}

All drivers who were based in Mekelle city with a legal driving licence and who were driving taxi, Bajaj (three wheel taxi), private owned car and governmental car in Mekelle city were included in the study. Heavy truck drivers, drivers who were not working and sick during the study period, those who drive more than two vehicle types and those who came from other areas to Mekelle city were excluded from the study.

The sample size was calculated from a previous study, where the prevalence of RTA was reported, $\mathrm{p}=22 \%$ in Mekelle city. ${ }^{12}$ Using $5 \%$ marginal error and $95 \%$ CI by the following formula: $\mathrm{n}=(\mathrm{Z} \alpha / 2)^{2} \mathrm{P}(\mathrm{P}-1) / \mathrm{D}^{2}$

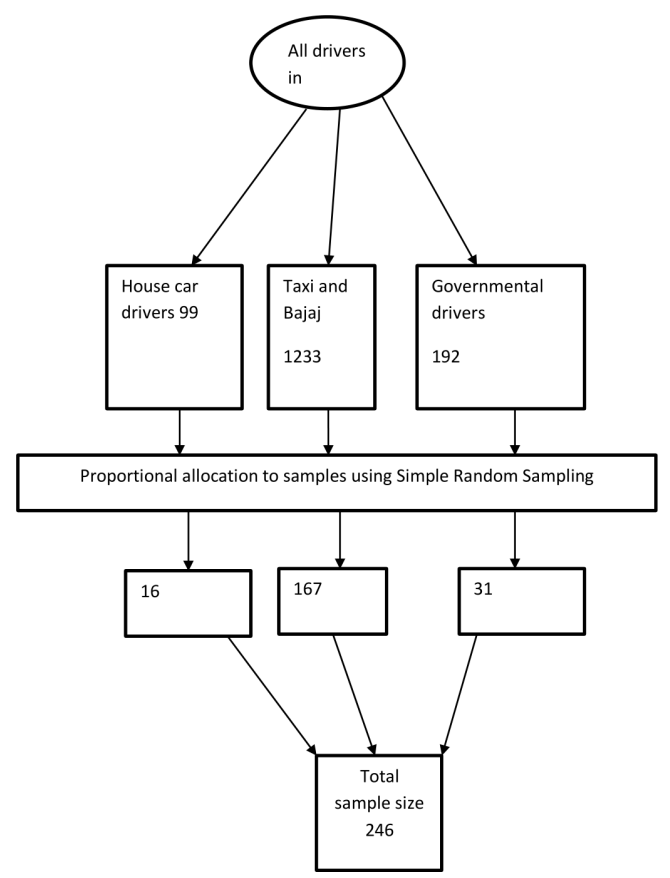

Figure 1 Sampling procedure. Schematic presentation of the sampling procedure.

Where $\mathrm{n}=$ minimum sample size required

$\mathrm{Z}=$ standard score corresponding to $95 \%$ CI

$\mathrm{p}=$ assumed proportion of drivers

$\mathrm{D}=$ margin of error (precision) $5 \%$

$\mathrm{n}=3.84 \times 0.1716 / 0.0025=263$

Since the source population was less than 10000 (ie, 1500 ), sample size correction formula was used: $\mathrm{nf}=\mathrm{n} / 1+$ $(\mathrm{n} / \mathrm{N})$

Where $\mathrm{nf}=$ desired sample size

$\mathrm{n}=$ calculated sample size

$\mathrm{n}=$ total population

$\mathrm{nf}=\mathrm{n} / 1+(\mathrm{n} / \mathrm{N})=263 / 1+(263 / 1500)=263 / 1.175=223.8 \sim$ 224

By adding $10 \%$ contingency for non-response, the sample size was $224+22=246$.

\section{Sampling procedures}

A sampling frame was constructed by a vehicle plate number, which was obtained from Mekelle city transport office. The frame was subcategorised based on the type of the vehicle as a taxi, Bajaj, governmental vehicles and private/house vehicles. Subsamples were calculated for each category of vehicles proportional to the number of vehicles in the respective categories. Then, study subjects were selected using simple random sampling method (see figure 1).

\section{Data collection procedures and tools}

The study subjects (drivers) were traced and interviewed for data collection. The drivers were traced at their destination for taxi and Bajaj, house cars in their working area and governmental cars at their offices using the car plate number. A structured interviewer administered questionnaire, adapted from different literatures, was used. The questionnaire was initially prepared in English and was 
translated into the local language Tigrigna. The instrument included: sociodemographic characteristics of drivers, risky behaviours factors and other variables which has a bearing on RTA. Trained data collectors and supervisors handled the data collection process.

\section{Patient and public involvement}

Drivers in Mekelle city were involved in the study.

\section{Data quality control}

Pre-est was done on 5\% of the sample at Adigrat town, Tigray region. Based on the pretest findings, necessary corrections were made to the questionnaire. Adequate supervision was undertaken by the supervisors and principal investigator during the data collection. Daily spotchecking of the filled questionnaires for errors or any incompleteness was done by the supervisors and the principal investigator.

\section{Data management and analysis}

The collected data were entered and cleaned in Microsoft excel 2007. Then, the data were exported and analysed using STATA V.12. Values of categorical variables were presented as frequencies and percentages. All statistical tests were performed at the $5 \%$ significance level.
The dependent variable was a occurrence RTA within 2 years which was dichotomised into yes (labelled ' 1 ') and no (labelled ' 0 '). To prevent recall bias respondents were reinforced to remember the occurrence of RTA in the previous 2 years. Each independent variable was cross-tabulated and further evaluated for association in the bivariate binary logistic regression. Finally, variables significant in the bivariate analysis were entered into multivariable binary logistic regression analysis to identify determinants of RTA. Variables on risky behaviours, traffic safety rules and some other personal characteristics were used to interpret the adjusted OR (AOR) in the multivariate analysis under the adjustment of the sociodemographic variables. The final model was developed using a stepwise logistic regression.

The confounding effect of the explanatory variables was checked using forward and backward elimination techniques and any variable above $20 \%$ change of coefficient was considered as a confounder. Multicollinearity was checked using variance inflation factor (VIF) at a cut-off value of 10 . Variables with greater than $10 \mathrm{VIF}$ value were handled by removing the most intercorrelated variable(s) from the model and substitute their cross product as an interaction term. Final model fitness was checked using the

Table 1 Sociodemographic and economic characteristics of drivers in Mekelle city, Northern Ethiopia, 2015

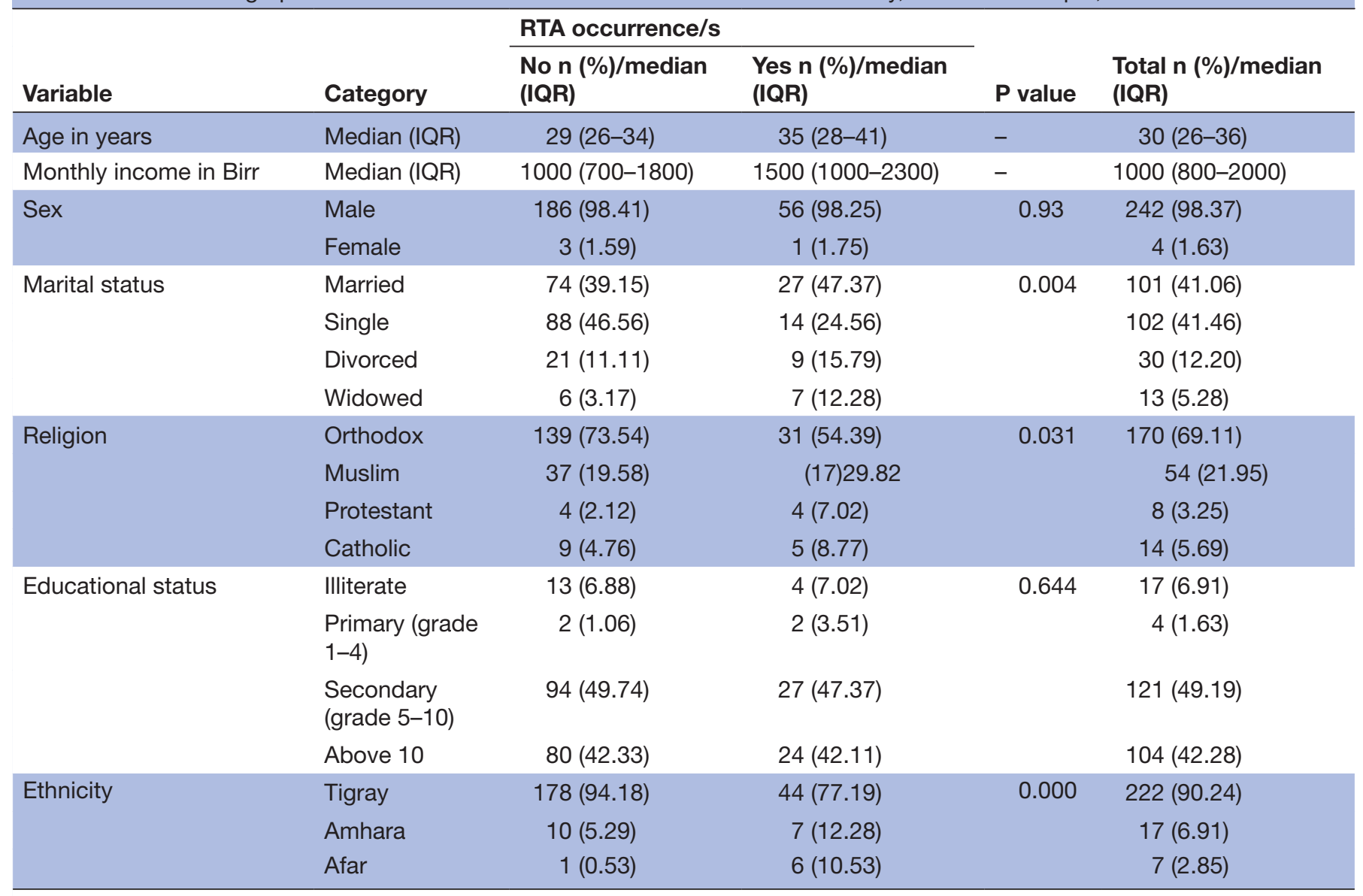

$n=246$.

RTA, road traffic accident. 
Table 2 Characteristics and setting of RTA in Mekelle city, Northern Ethiopia, 2015

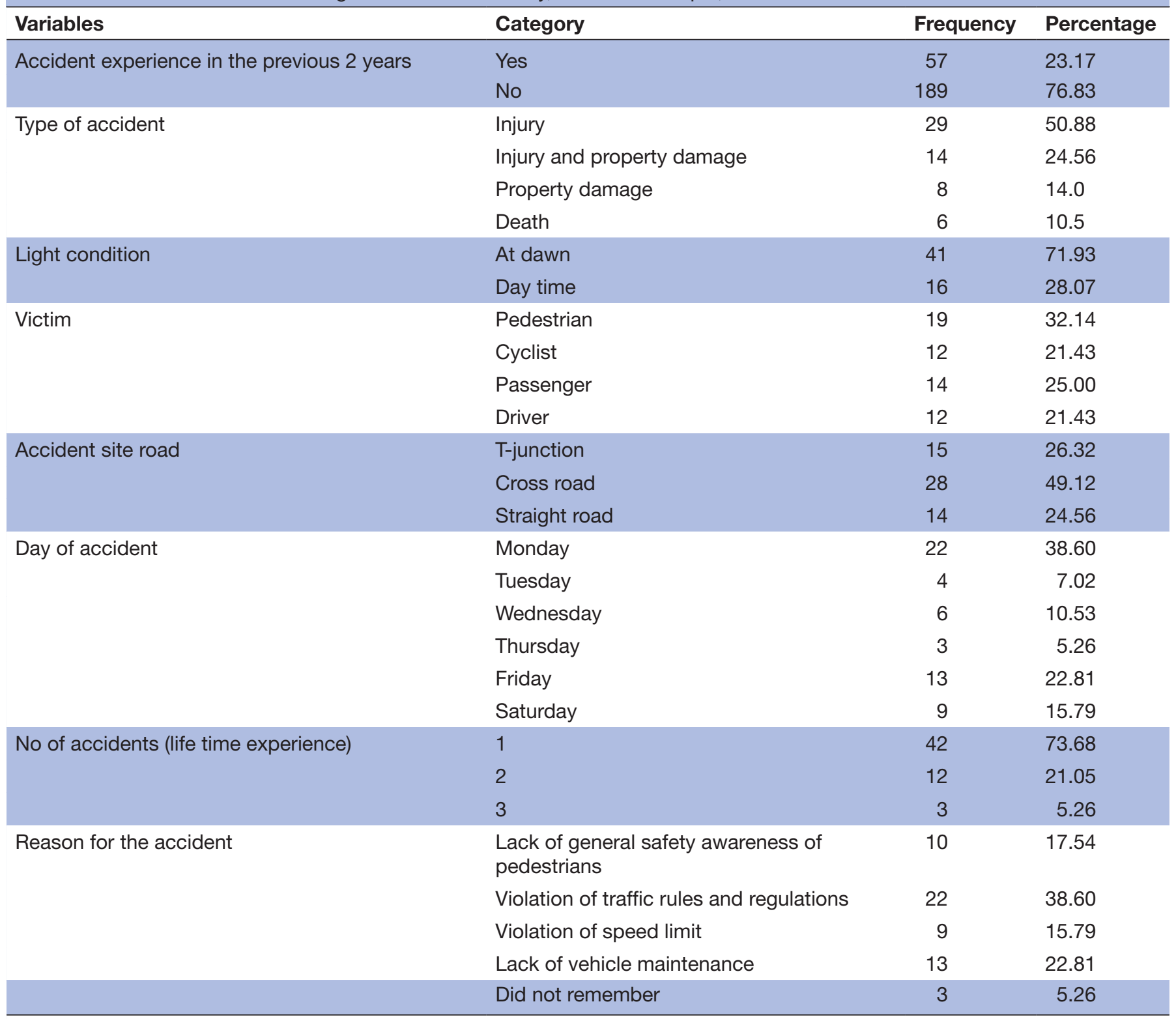

$n=246$.

RTA, road traffic accident.

Hosmer-Lemeshow method. Receiver operating characteristic (ROC) curve was used to show how much the independent variables in the final model predicted the dependent variable.

\section{RESULTS}

\section{Sociodemographic characteristics of the respondents}

The response rate was $100 \%$. The median (IQR) age of the respondents was 30 (10) years. The majority of study participants $(98.37 \%)$ were males. Regarding the marital status of the respondents, 102 (41.46\%), 101 (41.06\%), 30 $(12.20 \%)$ and $13(5.28 \%)$ were divorced, married, single and widower, respectively. The majority of the drivers, 170 (69.11\%) were Christian Orthodox, followed by Muslims, $54(21.95 \%)$. With regard to their educational status,
$225(91.46 \%)$ had attained at least grade 5 . The median (IQR) monthly income (in Birr) of the study participants was 1000 (1200) (table 1).

\section{Magnitude of RTAs}

Among all the drivers, 57 (23.17\%) had encountered RTA in the past 2 years from the time of the current study. Most of the accidents happened on Monday, 22 (38.60\%) and Friday, 13 (22.81\%) even though accidents were reported in all the 7 days. About 22/57 (38.60\%), 13/57 (22.81\%), $10 / 57(17.54 \%)$ and $9 / 57(15.79 \%)$ of the reported causes of RTAs were due to violation of traffic laws, lack of vehicle maintenance, lack of general safety awareness on pedestrians and violation of speed limit . A significant number of the accidents, 25/57 (43.86\%) happened at 
Table 3 Risky driving behaviours, infrastructure setup and practices among drivers in Mekelle city, Northern Ethiopia, 2015

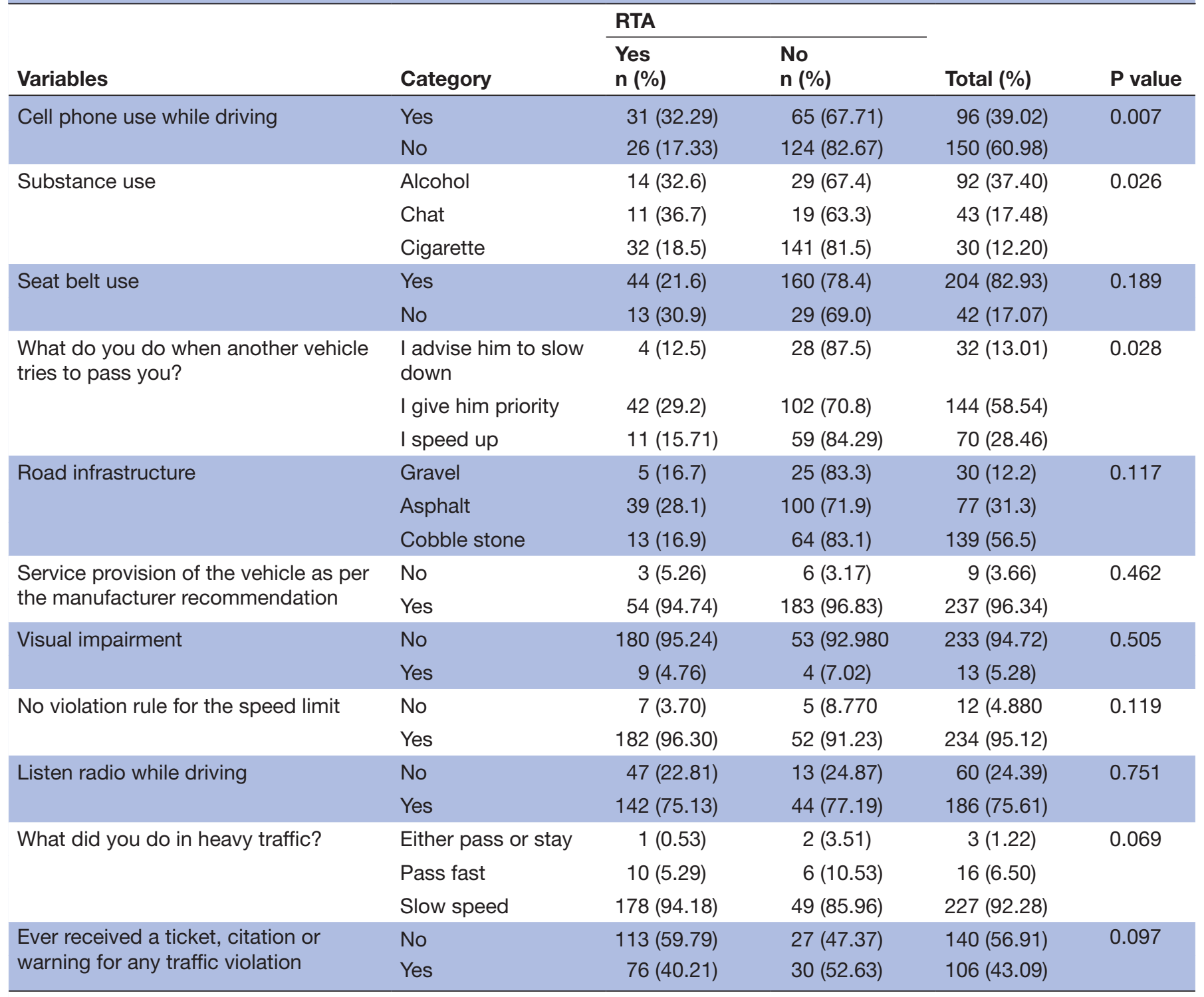

$n=246$.

dawn. Pedestrians and cyclists constituted the major share of the RTA victims, 31/57 (54.40\%). About three-fourths of the accidents, $43 / 57(75.44 \%)$ happened at either T-junction road or cross road (table 2 ).

\section{Risky driving behaviours, infrastructure setup and practices}

Concerning risky driving behaviours, 92 (37.40) of the drivers drunk alcohol before driving. About 43 (17.48\%) of the drivers were chat chewers and 30 (12.20\%) were smokers. More than one-third of the drivers, $96(39.02 \%)$ ever reported that they used cell phone for communication while driving. The prevalence of RTA among drivers was $3.29 \%, 32.6 \%, 36.7 \%, 18.5 \%$ and $21.6 \%$ among cell phone users, alcohol consumers, chat chewers, cigarette smokers and seat belt users while driving respectively. However, the prevalence of RTA among the drivers who do not use cell phone and seat belt were $17.33 \%$ and $30.9 \%$ respectively (table 3 ).

\section{Factors associated with RTAs}

In the bivariate analysis age, being married, being single, driving governmental vehicle, alcohol use, other substances other than alcohol use, cell phone use during driving, drivers' years of experience and vehicle service were significantly associated with RTAs at 95\% CI. Multivariable binary logistic regression analysis showed that drivers who drove after consuming alcohol were 2.29 (AOR 2. 29; $95 \%$ CI 1.08 to 4.85 ) times more likely to have RTA compared with drivers who did not consume alcohol. Drivers who drove governmental vehicles were 4.16 (AOR $4.16 ; 95 \%$ CI 1.48 to 11.70 ) times more likely to have RTA compared with drivers of privately owned vehicles. As the driver's experience increased by 1 year, the probability of RTA decreased by $26 \%$ (AOR 0. 74; $95 \%$ CI 0.60 to 0.90 ) (table 4 ). 


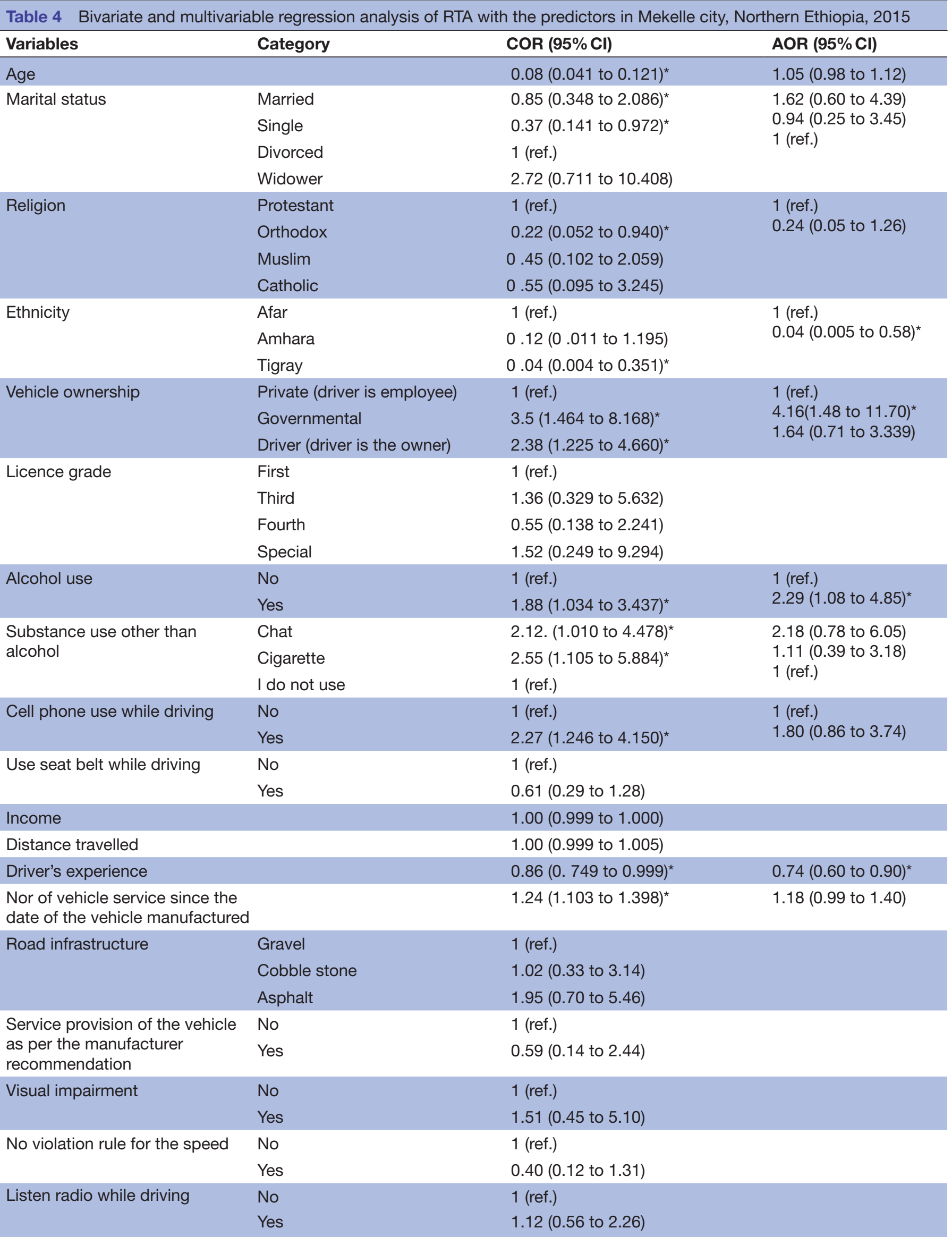


Table 4 Continued

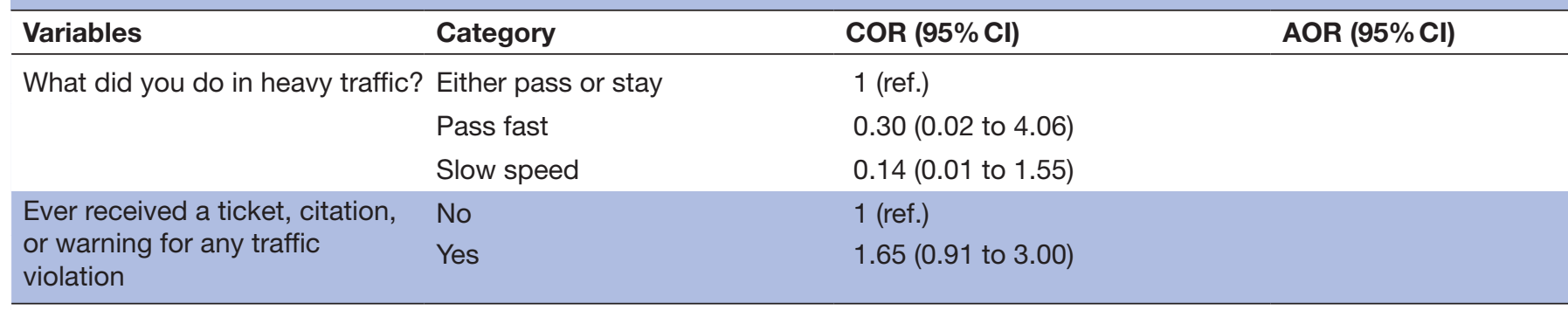

$\mathrm{n}=246$.

${ }^{*} \mathrm{P}<0.05$.

RTA, road traffic accident.

The residuals were checked for influential outlier observations and the result showed that there were no suspicious influential outlier observations. Hosmer-Lemeshow test showed a $\chi^{2}$ value of $9.41(p=0.3085)$ which is greater than 0.05 . The null hypothesis is not to be rejected, which implies that the model estimates adequately to fit the data at an acceptable level. The area under ROC curve was 0.7536 (see figure 2). The predicting power of the independent variables for the dependent variable was $75.36 \%$. Therefore, it can be concluded that the model fits the data reasonably well. No confounding factor was found.

\section{DISCUSSION}

The main aim of the study was to assess the magnitude and determinants of RTAs among drivers in Mekelle city, Tigray, Northern Ethiopia. This study showed 23.17\% of the drivers have reported having RTA in the previous 2 years. Ownership of the vehicles, driving after taking alcohol, driver's experience, used cell phone while driving were the determinants for RTAs among the drivers.

The study revealed that the magnitude of self-reported RTA in Mekelle city was $23.17 \%$. There was a slight

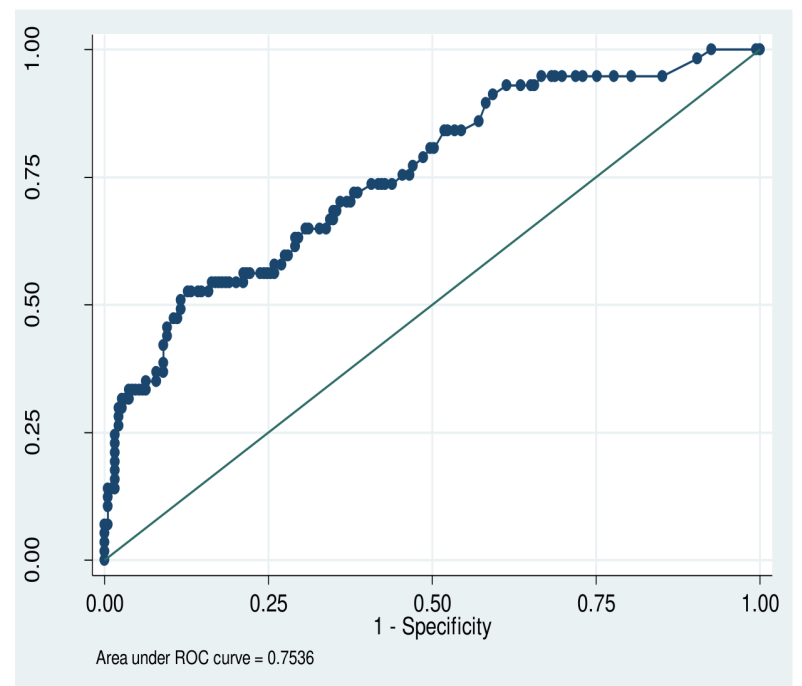

Figure 2 ROC curve predicting power of the independent variables for the dependent variable. ROC, receiver operating characteristic. increment of accidents in this study compared with the previous study done in Mekelle city, which showed that the prevalence of RTA was $22 \% .{ }^{12}$ However, it is lower when compared with a similar study conducted in the same city among taxi drivers with four wheels, of which $26.4 \%$ of them reported RTA encounter within the past 3 years. ${ }^{17}$ This variation might be due to the fact that the city is expanding where the population size is increasing. Or it might be due to the differences in the RTAs report period where the current study included reports of RTA in the past 2 years from the time of the study. About three-fourths $(75.44 \%)$ of the accidents of this study, happened at either T-junction or cross roads. The finding of this study is higher as compared with recent statistics from USA and India which showed, approximately $55 \%$ of the total traffic crashes and $23 \%$ of crashes with fatalities in urban areas in the USA occur at intersections and approximately $32 \%$ of urban traffic crashes take place at intersections in India. ${ }^{18}$ This difference might be due to infrastructure differences like traffic lights in the intersections of the roads. Because traffic signals do help to prevent collisions if obeying for traffic rules by the drivers. ${ }^{19}$ In this study about $22 / 57$ (38.60\%), 13/57 (22.81\%), $10 / 57(17.54 \%)$ and $9 / 57(15.79 \%)$ of the reported causes of RTAs were due to violation of traffic laws, lack of vehicle maintenance, lack of general safety awareness on pedestrians and violation of speed limit. This finding is similar with the study on the comparative analysis of literature concerning road safety, which showed that the causes include: lack of control and enforcement concerning implementation of traffic regulation (primarily driving at excessive speed, driving under the influence of alcohol and not respecting the rights of other road users (mainly pedestrians and cyclists), lack of appropriate infrastructure and unroadworthy vehicles. ${ }^{20}$ This is because, obeying traffic laws are designed to protect the drivers and other people, animals or from destruction of properties around the road and it self the road. In other words by knowing the rules of the road, practising good driving skills and generally taking care as a road user can help a vital role in preventing a crash.

This study identified that ownership of the vehicles was found to be predictor of RTA. RTA was 3.78 times 
more likely among those who drove governmental vehicles. A study on Arab gulf countries as compared with other countries showed that vehicle ownership levels and safety parameters in both developed and low-income and middle-income countries is presented to highlight the relative seriousness of the road safety situation in different countries. ${ }^{14}$ The possible justification for this to be happen might be due to the fact that governmental drivers might violate the traffic rules and speed up to arrive timely at workplace especially at the peak hours.

This study revealed that driving after taking alcohol was found to be an aggravating factor for RTA. Drivers who drove after consuming alcohol were 2.29 more likely to have RTA compared with those who do not consume alcohol. This finding is similar to a similar study which showed that individuals who drank alcohol were 3.2 times more likely to encounter RTA. ${ }^{21}$ It was also supported by the Great Britain department for Transport provisional estimates for 2013 which showed that between 230 and 290 people were killed in accidents in Great Britain where at least one driver was over the drink drive limit. ${ }^{22}$ Another study also showed that impairments from alcohol was associated with traffic accident of crashes and deaths. ${ }^{23} 24$ This might be due to the nature of alcohol that has a range of psychomotor and cognitive effects, including attitude, judgement, vigilance, perception, reaction and controlling. ${ }^{25}$ This can increase accident risk by lowering cognitive processing, coordination, attention, vision and hearing.

This study has also revealed that as driver's experience increases by 1 year, the probability of getting RTA decreased by 26 percent. This finding was similar to the finding of a study in 2003 which showed that as the drive miles and experience increases, the probability of selfreported crash decreased. ${ }^{26}$ This might be due to the anticipation of potentially hazardous traffic situations, which require years of practice.

The likelihood of RTA was 1.8 times higher among drivers who used cell phone while driving compared with these who do not use. This study is consistent with a previously done study in Mekelle city. ${ }^{17}$ Other studies have also reported that drivers distracted by mobile devices such as smartphones and/or other in-vehicle devices are at risk for a serious negative outcomes. ${ }^{27-29}$ A similar study indicated that telephone use while driving increases the likelihood of RTA/crash by a factor of four, while texting by around 23 times. ${ }^{30}$ This is because of loss of attention to surroundings while driving.

The findings of this study showed visual impairment was not found to be a predictor variable for RTA. But a study done in Ibadan town Nigeria showed that drivers who had visual impairment were 1.6 times more likely to encounter RTA. ${ }^{31}$ Therefore, this needs further investigation.

The strength of this study is that data quality was assured under close supervision of the principal investigators during both data entry and data collection time. Appropriate statistical methods were used to present the findings of the study. Despite this strength, the study has certain limitations. Due to cross-sectional study design nature, establishing causality is not possible. In addition to that, there may be recall bias and the analysis of this study misses some important variables like quality of the vehicles and road safety.

\section{CONCLUSION}

The magnitude of RTA was high. The intersections of the roads were the main cause of RTAs. Violation of traffic laws, lack of vehicle maintenance and lack of general safety awareness on pedestrians were the dominant reported causes of RTAs. Driving a governmental vehicle and alcohol consumption were the factors associated with RTA. Monitoring blood alcohol level of drivers should be in place. Education on traffic laws and regulations should be given to drivers on regular basis. In addition to that a holistic study should be done to identify the causes of RTA. Due to the similarities of the cities in North Ethiopia, this study can represent to other cities in Northern Ethiopia.

Acknowledgements We are glad to extend our gratitude to the data collectors and participants of the study. We would like to extend our gratitude to Mekelle University as well for funding the research.

Contributors ABW conceptualised and designed the study, involved in data analyses, acquisition of data, tabulating the data, interpretation of data, preparing tables and figures, and critically revising the manuscript. AAD and TWW have involved in interpretation of data, Supervision, administration, drafting the initial manuscript and critically revising the manuscript. AAD has primary responsibility for final content and involved in final review. All authors read and approved the final manuscript.

Funding This study was funded by Mekelle University for research and community services.

Competing interests None declared.

Patient consent for publication Not required.

Ethics approval Ethical clearance and approval was given by Mekelle University, school of public health Ethical Review Committee with the approval number of ERC 0017/2014

Provenance and peer review Not commissioned; externally peer reviewed.

Data availability statement Data are available on reasonable request. The dataset of the study findings is available from the corresponding author on reasonable request.

Open access This is an open access article distributed in accordance with the Creative Commons Attribution Non Commercial (CC BY-NC 4.0) license, which permits others to distribute, remix, adapt, build upon this work non-commercially, and license their derivative works on different terms, provided the original work is properly cited, appropriate credit is given, any changes made indicated, and the use is non-commercial. See: http://creativecommons.org/licenses/by-nc/4.0/.

\section{ORCID iDs}

Abraham Aregay Desta http://orcid.org/0000-0002-1505-7451

Tewolde Wubayehu Woldearegay http://orcid.org/0000-0001-7619-1112

\section{REFERENCES}

1 Organization for Economic Cooperation and Development (OECD). Health statistics 2019 definitions, sources and methods, 2019. Available: file:///C:/Users/lenovo/Downloads/HEALTH STAT 11 Injuries\%20in\%20road\%20traffic\%20accidents.pdf [Accessed 24 Nov 2019].

2 World Health Organization (WHO). Global status report on road safety. Geneva: WHO, 2018.

3 WHO. Projections of mortality and causes of death, 2015 and 2030. Geneva: WHO, 2013. http://www.who.int/healthinfo/ 
4 Foreman KJ, Marquez N, Dolgert A, et al. Forecasting life expectancy, years of life lost, and all-cause and cause-specific mortality for 250 causes of death: reference and alternative scenarios for 2016-40 for 195 countries and territories. Lancet 2018;392:2052-90.

5 Clifford J, THEOBALD C, Atkinson S. Evaluating the costs of incidents from the public sector perspective: a road safety policy research paper, 2016.

6 WHO. Global plan: decade of action for road safety 2011-2020. Geneva: WHO, 2010.

7 WHO. Global health expenditure database. Geneva: WHO, 2018. http://apps.who.int/nha/database

8 Nabi H, Consoli SM, Chastang J-F, et al. Type A behavior pattern, risky driving behaviors, and serious road traffic accidents: a prospective study of the GAZEL cohort. Am J Epidemiol 2005;161:864-70.

9 Abuhamoud MAA, Rahmat RAOK, Ismail A. Transportation and its concerns in Africa: a review. The Social Sciences 2011;6:51-63.

10 WHO. World health rankings. In: Live longer live better. Geneva: WHO, 2011.

11 WHO. World health rankings. In: Live longer live better. Genevea: WHO, 2013.

12 Hassen A, Godesso A, Abebe L, et al. Risky driving behaviors for road traffic accident among drivers in Mekele City, Northern Ethiopia. BMC Res Notes 2011;4:535.

13 Mekelle Town Police Commission Office. Report on road traffic accident Mekele. Mekelle: Police commission, 2014.

14 Bener A, Abu-Zidan FM, Bensiali AK, et al. Strategy to improve road safety in developing countries. Saudi Med J 2003;24:603-8.

15 United Nations. Transforming our world: the 2030 agenda for sustainable development. New York: United Nations, 2015.

16 Mekelle City Administration. Free traffic ranks. Mekelle: Mekelle City administration, 2019. http://mekelleadministration.gov.et.rankank. com

17 Asefa NG, Ingale L, Shumey A, et al. Prevalence and factors associated with road traffic crash among TAXI drivers in Mekelle town, Northern Ethiopia, 2014: a cross sectional study. PLoS One 2015;10:e0118675.

18 Khan MA, Agarwal PK, Chaki S. Strategies for safety evaluation of road intersection to have sustainable development. Journal of Advanced Research in Automotive Technology and Transportation System 2017;2:65-77.
19 Rhythm Engineering. 7 traffic signal myths Debunked. Available: https://rhythmtraffic.com/7-traffic-signal-myths-debunked/

20 Goniewicz K, Goniewicz M, Pawłowski W, et al. Road accident rates: strategies and programmes for improving road traffic safety. Eur $J$ Trauma Emerg Surg 2016;42:433-8.

21 Connor J, Norton R, Ameratunga S, et al. The contribution of alcohol to serious CAR crash injuries. Epidemiology 2004;15:337-44.

22 Great Britain Department for Transport. Estimates for reported road traffic accidents involving illegal alcohol levels: 2013 (second provisional) self-reported drink and drug driving for 2013/14. London: Great Britain Department for Transport, 2015. https:// assets.publishing.service.gov.uk/government/uploads/system/ uploads/attachment_data/file/402698/rrcgb-drink-drive-2013-prov. pdf

23 Shinar D. Traffic safety and human behavior. 2nd edition. Beersheba, Israel: Ben Gurion University of the Negev, 2017.

24 Brown T, Milavetz G, Murry DJ, Alcohol MDJ. Alcohol, drugs and driving: implications for evaluating driver impairment. Ann Adv Automot Med 2013;57:23-32.

25 Zhao X, Zhang X, Rong J. Study of the effects of alcohol on drivers and driving performance on straight road. Math Probl Eng 2014;2014:1-9.

26 Rolison JJ, Regev S, Moutari S, et al. What are the factors that contribute to road accidents? an assessment of law enforcement views, ordinary drivers' opinions, and road accident records. Accid Anal Prev 2018;115:11-24

27 Lipovac K, Đerić M, Tešić M, et al. Mobile phone use while driving-literary review. Transp Res Part F Traffic Psychol Behav 2017;47:132-42.

28 Caird JK, Willness CR, Steel P, et al. A meta-analysis of the effects of cell phones on driver performance. Accid Anal Prev 2008;40:1282-93.

29 Horrey WJ, Wickens CD. Examining the impact of cell phone conversations on driving using meta-analytic techniques. Hum Factors 2006;48:196-205.

30 Farmer CM, Braitman KA, Lund AK. Cell phone use while driving and attributable crash risk. Traffic Inj Prev 2010;11:466-70.

31 Bekibele CO, Fawole OI, Bamgboye AE, et al. Risk factors for road traffic accidents among drivers of public institutions in Ibadan, Nigeria. Afr J Health Sci 2007;14:137-42. 